\title{
El Perfil del Ingresante de las Carreras Profesionales y la Aptitud Vocacional de los Estudiantes del Primer Año en la UNJBG de Tacna en el Año 2011.
}

\author{
The Profile of Entrants to the Professional Careers and Vocational Skills \\ of First-Year Undergraduates in UNJBG of Tacna in 2011
}

\author{
${ }^{1}$ Dionicio Milton Chávez Muñoz, ${ }^{2}$ Julia Marina Mendoza Gómes
}

\begin{abstract}
RESUMEN:
Estudio denominado: El perfil del ingresante de las carreras profesionales y la aptitud vocacional de los estudiantes del primer año en la UNJBG de Tacna en el año 2011. Este trabajo tuvo como propósitos precisar el perfil profesional que exigen las carreras profesionales; especificar la aptitud vocacional de los estudiantes de primer año; $y$, determinar el grado de relación que existe entre el perfil del ingresante de las carreras profesionales y la aptitud vocacional de los estudiantes del primer año. El trabajo se realizó mediante un análisis documental de los currículos y el procesamiento de encuestas. Los resultados obtenidos son, respecto a las cualidades especificas expresadas en poseer los conocimientos previos, tener las habilidades técnico-formativas y ser emprendedor se ha encontrado un nivel adecuado entre $61 \%$ y $80 \%$ de certeza; la aptitud vocacional de los estudiantes, que se caracteriza por la motivación que posee, las habilidades académicas de que dispone y los conocimientos previos con que cuenta, están en un nivel adecuado entre $61 \%$ y $80 \%$ de certeza; $y$, la correlación entre el perfil profesional que se exige para el postulante, y la aptitud vocacional que tiene el ingresante, está alrededor de $80 \%$, es decir que el $80 \%$ de la aptitud vocacional del estudiante se explica linealmente por el perfil profesional que trae dicho ingresante.
\end{abstract}

Palabras clave: Perfil del ingresante, aptitud vocacional, motivación, conocimientos previos, habilidades técnico formativas.

\section{ABSTRACT:}

Study entitled: The profile of entrants to professional careers and vocational skills of first-year undergraduates in UNJBG of Tacna in 2011. The purposes of this study was to define the professional profile required by careers; specify the vocational aptitude for first-year undergraduates, and determine the point of the relationship between the entrant profile of careers and vocational aptitude for first-year undergraduates. The study was carried out through a documentary analysis of curricula and survey processing. The results obtained are, in regards to specific qualities expressed in the background, to possess technical skills training and to be initiative, was found a suitable level between $61 \%$ and $80 \%$ certainty, the vocational aptitude of students, which characterized by the motivation, academic skills and knowledge available, are at an adequate level between $61 \%$ and $80 \%$ certainty, and the correlation between the professional profile required for the applicant, and the vocational aptitude that the entrant has is about $80 \%$, that is $80 \%$ of the student's vocational aptitude explained linearly by the professional profile that the entrant brings.

Keywords: Profile of the entrant, vocational aptitude, motivation, previous knowledge, technical skills training.

\footnotetext{
Doctor en educación, Magister en Docencia Universitaria y Gestión Educativa. Licenciado en Matemática. Facultad de Ciencias. Universidad Nacional Jorge Basadre Grohmann de Tacna.

${ }^{2}$ Magister en Docencia Universitaria y Gestión Educativa, Licenciada en Matemática. Facultad de Ciencias. Universidad nacional Jorge Basadre Grohmann de Tacna.
} 


\section{I.INTRODUCCIÓN}

Este proyecto se generó por la inquietud de los investigadores ante la problemática que se ve en los estudiantes universitarios antes, durante y después de su formación profesional en la universidad, específicamente se dan casos en que el estudiante no responde al perfil exigido para estudiar una determinada carrera profesional, hay desmotivación, poco interés por el estudio y bajo rendimiento académico; en los primeros años de estudio se manifiesta una alta tasa de deserción o migración hacia otras carreras; los ingresantes no tiene las competencias y aptitudes necesarias para la carrera profesional, los perfiles profesionales de sus carreras están distantes de las aptitudes vocacionales que traen los estudiantes del primer año. Se planteó como Objetivo: Determinar la relación que existe entre el perfil del ingresante de las carreras profesionales y la aptitud vocacional de los estudiantes del primer año en la UNJBG de Tacna.

\section{MATERIALES Y MÉTODOS}

Se ha realizado una investigación relacional en base a encuestas aplicadas a los estudiantes y análisis documentario de los perfiles profesionales que se exponen en los Planes curriculares. La población estuvo conformado por los estudiantes del primer año de las 27 Escuelas académico Profesionales de la UNJBG y la muestra estuvo constituida por 15 Escuelas. La variable independiente, perfil del ingresante ha sido procesada para determinar el grado de proximidad al nivel exigido por la Carrera profesional; la variable dependiente, aptitud vocacional de los estudiantes ha sido procesada para determinar el grado de cumplimiento respecto a un modelo ideal. Se aplica un análisis correlacional de variables para determinar el grado de relación entre las dos variables.

\section{RESULTADOS}

Se registrarán los datos procesados, tomando como base la Tabla $\mathrm{N}^{\circ} 01$ donde se muestran la escala del perfil que puede alcanzar un estudiante al ingresar a la universidad. Dicha escala para el perfil del estudiante tiene una expresión numérica con valores de 1 al 5 , una expresión porcentual y una expresión cualitativa.

Tabla $N^{\circ}$ 01: Perfil alcanzado por el estudiante.

\begin{tabular}{|c|c|l|}
\hline \multicolumn{3}{|c|}{ ESCALA: PE RFIL PROFESIONA L PARA E L } \\
E STUDIAN TE
\end{tabular}

La variable independiente: El perfil profesional de las carreras profesionales de la UJ/NBG. Tiene los siguientes indicadores:
- Características de un estudiante universitario.

- Cualidades generales del estudiante universitario.

- Cualidades específicas del estudiante universitario.

Se muestra aquí, como parte de la exigencia del perfil de las cerreras profesionales, los indicadores para cualquier estudiante universitario; los dos primeros indicadores especificado en "características del estudiante universitario" y "cualidades generales del estudiante universitario", son invariantes para todo estudiante universitario; $y$, el tercer indicador "cualidades específicas del estudiante universitario" es diferente para cada carrera profesional, pero fijo en cada una de ellas porque es la exigencia particular que debe poseer un estudiante que lo caracteriza como estudiante de dicha carrera profesional.

La variable dependiente: $\mathrm{La}$ aptitud vocacional de los estudiantes del primer año, tiene los indicadores que se muestran en la Tabla $\mathrm{N}^{\circ} 02$.

Tabla $\mathrm{N}^{\circ} \mathbf{0 2}$ : Indicadores de la variable dependiente.

\begin{tabular}{|c|l|}
\hline $\mathbf{N}^{\circ}$ & \multicolumn{1}{|c|}{ Indicadores: } \\
\hline 1 & Conocimientos previos generales \\
\hline 2 & Habilidades académicas \\
\hline 3 & Motivación del estudiante \\
\hline 4 & Actitudes del estudiante \\
\hline 5 & Aptitudes del estudiante \\
\hline 6 & Práctica de valores \\
\hline 7 & Conocimientos previos específicos \\
\hline 8 & Habilidades técnico formativas \\
\hline 9 & Emprendedor - innovador \\
\hline
\end{tabular}

En seguida se muestra la aptitud del estudiante como resultado de su opinión frente a los indicadores de la variable independiente exigida para cada carrera profesional; dicha aptitud se desprende del análisis de los datos procesados expresados en los indicadores: perfil del ingresante de cada carrera profesional, habilidades académicas y motivación del estudiante.

Los resultados se presentan en las Tablas desde la Tabla $\mathrm{N}^{\circ} 03$ hasta la Tabla $\mathrm{N}^{\circ} 09$. Estas están clasificadas por facultades mostrándose el promedio de cumplimiento de los indicadores precisados para cada Escuelas AcadémicoProfesionales que conforman la Facultad.

\section{Presentación general de los resultados.}

Tabla $\mathrm{N}^{\circ}$ 3: $\mathrm{La}$ aptitud vocacional de los estudiantes del primer año: Facultad de Ingeniería.

\begin{tabular}{|l|l|r|}
\hline $\mathbf{N}^{\circ}$ & Indicadores & $\%$ \\
\hline 1 & Conocimientos previos generales & 68,6 \\
\hline 2 & Habilidades académicas & 73,4 \\
\hline 3 & Motivación del estudiante & 73,6 \\
\hline 4 & Actitudes del estud iante & 76 \\
\hline 5 & Aptitudes del estudiante & 76,1 \\
\hline 6 & Práctica de valores & 79,4 \\
\hline 7 & Conocimientos previos específicos & 72,5 \\
\hline 8 & Habilidades técnico form ativas & 80,6 \\
\hline 9 & Emprendedor & 74,4 \\
\hline & Promedio total & $\mathbf{7 5 , 0}$ \\
\hline
\end{tabular}


Tabla $\mathrm{N}^{\circ}$ 4: La aptitud vocacional de los estudiantes del primer año: Facultad de Ciencias Jurídicas y

Empresariales.

\begin{tabular}{|l|l|r|}
\hline $\mathbf{N}^{\circ}$ & Indicadores & $\mathbf{\%}$ \\
\hline 1 & Conocimientos previos generales & 77 \\
\hline 2 & Habilidades a cadémicas & 77,5 \\
\hline 3 & Motivación del estudiante & 77,3 \\
\hline 4 & Actitudes del estud iante & 83,4 \\
\hline 5 & Aptitudes del estudiante & 83,9 \\
\hline 6 & Práctica de valores & 90,9 \\
\hline 7 & Conocimientos pre vios específicos & 74,1 \\
\hline 8 & Habilidades técnico formativas & 80 \\
\hline 9 & Emprendedor - innovador & 87,9 \\
\hline & Promedio total & $\mathbf{8 2 , 0}$ \\
\hline
\end{tabular}

Tabla $N^{\circ}$ 5: La aptitud vocacional de los estudiantes del primer año: Facultad de Ciencias Agropecuarias.

\begin{tabular}{|l|l|c|}
\hline $\mathbf{N}^{\circ}$ & Indicadores & $\%$ \\
\hline 1 & Conocimientos previos generales & 70,5 \\
\hline 2 & Habilidades aca démicas & 77,5 \\
\hline 3 & Motivación del estudiante & 73 \\
\hline 4 & Actitudes del estudiante & 80 \\
\hline 5 & Aptitudes del estudiante & 81 \\
\hline 6 & Práctica de valores & 89,5 \\
\hline 7 & Conocimientos previos específic os & 68,5 \\
\hline 8 & Habilidades técnico formativas & 85,5 \\
\hline 9 & Emprendedor - innovador & 86,5 \\
\hline & Promedio total & $\mathbf{7 8 , 7}$ \\
\hline
\end{tabular}

Tabla $N^{\circ}$ 6: La aptitud vocacional de los estudiantes del primer año: Facultad de Ciencias de la Salud.

\begin{tabular}{|l|l|c|}
\hline $\mathrm{N}^{\circ}$ & Indicadores & $\%$ \\
\hline 1 & Conocimientos previos generales & 70,9 \\
\hline 2 & Habilidades aca démicas & 75,8 \\
\hline 3 & Motivación del estudiante & 69,7 \\
\hline 4 & Actitudes del estud iante & 78,9 \\
\hline 5 & Aptitudes del estudiante & 81,2 \\
\hline 6 & Práctica de valores & 86,1 \\
\hline 7 & Conocimientos previos específicos & 78,5 \\
\hline 8 & Habilidades técnico formativas & 84,5 \\
\hline 9 & Emprendedor - innovador & 83 \\
\hline & Promedio total & $\mathbf{7 8 , 9}$ \\
\hline
\end{tabular}

Tabla $N^{\circ}$ 7: La aptitud vocacional de los estudiantes del primer año: Facultad de Educación, comunicación $\mathrm{y}$ humanidades.

\begin{tabular}{|l|l|c|}
\hline $\mathbf{N}^{\circ}$ & Indicadores & $\mathbf{\%}$ \\
\hline 1 & Conocimientos previos generales & 77 \\
\hline 2 & Habilidades académicas & 81,3 \\
\hline 3 & Motivación del estudiante & 79,6 \\
\hline 4 & Actitudes del estudiante & 81,7 \\
\hline 5 & Aptitudes del estudiante & 82,1 \\
\hline 6 & Práctica de valores & 86,2 \\
\hline 7 & Conocimientos previos específicos & 83,5 \\
\hline 8 & Habilidades técnico formativas & 80,1 \\
\hline 9 & Emprendedor - innovador & 86,7 \\
\hline & Promedio total & $\mathbf{8 1 , 3}$ \\
\hline
\end{tabular}

Tabla $N^{\circ} 8$ : La aptitud vocacional de los estudiantes del primer año: Facultad de Ciencias.

\begin{tabular}{|l|l|c|}
\hline $\mathbf{N}^{\circ}$ & Indicadores & $\%$ \\
\hline 1 & Conocimientos previos generales & 68,9 \\
\hline 2 & Habilidades académicas & 73,6 \\
\hline 3 & Motivación del estudiante & 66,4 \\
\hline 4 & Actitudes del estudiante & 79 \\
\hline 5 & Aptitudes del estudiante & 81,8 \\
\hline 6 & Práctica de valores & 88,6 \\
\hline 7 & Conocimientos previos específicos & 86,7 \\
\hline 8 & Habilidades técnico formativas & 80 \\
\hline 9 & Emprendedor - innovador & 80 \\
\hline & Promedio total & $\mathbf{7 9 , 1}$ \\
\hline
\end{tabular}

Tabla $N^{\circ}$ 9: La aptitud vocacional de los estudiantes del primer año: facultad de Ingeniería Civil,

Arquitectura y Geología-Geotecnia.

\begin{tabular}{|l|l|r|}
\hline $\mathbf{N}^{\circ}$ & Indicadores & \multicolumn{1}{c|}{} \\
\hline 1 & Conocimientos previos generales & 72,8 \\
\hline 2 & Habilidades académicas & 77,9 \\
\hline 3 & Motivación del estudiante & 74,8 \\
\hline 4 & Actitudes del estud iante & 78,7 \\
\hline 5 & Aptitudes del estudiante & 82 \\
\hline 6 & Práctica de valores & 82,5 \\
\hline 7 & Conocimientos previos específicos & 81 \\
\hline 8 & Habilidades técnico formativas & 79,3 \\
\hline 9 & Emprendedor - innovador & 81,5 \\
\hline & Promedio total & $\mathbf{7 8 , 3}$ \\
\hline
\end{tabular}

\section{DISCUSIÓN.}

Respecto a precisar el perfil profesional que exigen las diferentes carreras profesionales en la UNJBG, encontramos en su mayoría una falta de precisión, por lo que los investigadores han tomado la decisión de adecuar como referente de exigencia un perfil promedio de las diferentes Escuelas Profesionales en la región y el país, que proponen sus perfiles en cada carrera estableciendo un perfil ideal, adaptado al contexto regional; este ha sido corroborado y validado por juicio de expertos en temas curriculares y de especialidad.

Respecto a cualidades específicas de los estudiantes, es emprendedor, tiene las habilidades técnico-formativas y posee los conocimientos previos específicos, en ese orden se encuentra en un nivel adecuado, ubicándose entre $61 \%$ y $80 \%$ de certeza.

El ingresante tiene en promedio un $30 \%$ de los aspectos considerados como indicadores que no los cumple plenamente para ubicarsecomo debidamente preparado e iniciar estudios universitarios en su Carrera profesional.

Respeto a las características generales del estudiante universitario que se exigen para las carreras profesionales de la UNJBG de Tacna, se ha alcanzado el nivel adecuado. 
Del mismo modo, en cuanto a las cualidades generales del estudiante universitario se ha alcanzado el nivel adecuado. En cuanto a las cualidades especificas del estudiante, de cada carrera profesional se ha tenido un logro también adecuado.

Respecto a la correlación entre el perfil que se exige para el postulante de cada carrera profesional y la aptitud vocacional que tiene el ingresante es de 0,78 . Lo cual quiere decir que el $78 \%$ de la aptitud vocacional de estudiante se explica linealmente por el perfil profesional que trae dicho estudiante a la Escuela Académico profesional a la cual ingresa.

Respecto a la variable dependiente que se precisa en la aptitud vocacional de los estudiantes del primer año, han logrado un nivel adecuado para la mayoría de carreras profesionales de la universidad.

Tabla $N^{\circ}$ 10: Perfil y Aptitud Académica por Escuelas, y su coeficiente de correlación.

\begin{tabular}{|l|c|c|c|}
\hline \multirow{2}{*}{ Escuela } & \multicolumn{2}{|c|}{ Promedio en \% } & \multirow{2}{*}{$\begin{array}{c}\text { Coeficiente } \\
\text { correlación }\end{array}$} \\
\cline { 2 - 3 } & Perfil & $\begin{array}{c}\text { Aptitud } \\
\text { vocacional }\end{array}$ & \\
\hline ESMI & 81.4 & 81.2 & 0.85 \\
\hline ESME & 76.4 & 76.0 & 0.74 \\
\hline ESIO & 71.7 & 71.9 & 0.62 \\
\hline ESMC & 79.1 & 71.4 & 0.69 \\
\hline ESAD & 81.9 & 81.9 & 0.78 \\
\hline ESDE & 84.9 & 85.2 & 0.72 \\
\hline ESCO & 88.4 & 80.7 & 0.70 \\
\hline ESIA & 79.6 & 79.1 & 0.79 \\
\hline ESOB & 78.9 & 78.6 & 0.76 \\
\hline ESEN & 79.2 & 78.9 & 0.50 \\
\hline ESOD & 79,0 & 78,7 & 0,85 \\
\hline ESCC & 75,3 & 75,3 & 0,68 \\
\hline ESBM & 78,6 & 78,3 & 0,76 \\
\hline ESIC & 78,1 & 78,0 & 0,71 \\
\hline ESGE & 80,6 & 80,2 & 0,55 \\
\hline Promedio & $\mathbf{7 8 , 5}$ & $\mathbf{7 8 , 4}$ & $\mathbf{0 , 7 1}$ \\
\hline General & $\mathbf{2}$ & \\
\hline
\end{tabular}

En la Tabla $\mathrm{N}^{\circ} 10$, se detalla cada Escuela Profesional con los perfiles y la aptitud Vocacional que han sido previamente procesados y en donde logramos ver los porcentajes de cumplimiento respecto al total $100 \%$. Se muestra también el nivel de correlación entre las dos variables de estudio.

El perfil que tiene el alumno posee un grado de deficiencia dado que no cumple planamente con el perfil exigido por las carreras profesionales, un $30 \%$ de los estudiantes desertan de sus carreras, se explica por el hecho de que no cubren el perfil de la carrera. Coincidiendo con León Trahtemberg en el hecho que los estudiantes universitarios tienen serias deficiencias y carencias que hacen que enfrentar una carrera universitaria le sea complicado.

La Aptitud Vocacional está expresada como una dimensión que conjuga problemas de identidad de la persona que ponen en evidencia la dificultad de elegir su carrera. Mucho más si tiene influencias externas que distorsionan la realidad y bajo esas influencias eligen su carrera.

Por otro lado, existe un alto número de estudiantes desaprobados, que del mismo modo se explica por el incumplimiento del perfil del estudiante, cuando éste hace vida universitaria. Esta investigación tuvo ese cuidado iniciándose la toma de datos después del primer semestre cuando el estudiante ya tiene definido el continuar con la carrera iniciada.

Finalmente voces experimentadas hacen ver que un alto porcentaje de estudiantes egresan de las instituciones educativas con capacidades de poder afrontar más de una carrera profesional.

La correlación es bastante aceptable como se observa en la Tabla $\mathrm{N}^{\circ} 10$, $\tan$ solo dos de las escuelas presentan una mediana correlación; $y$, permite afirmar que el perfil profesional efectivamente se relaciona con la orientación vocacional de que dispone el estudiante.

\section{CONCLUSIONES}

PRIMERA. Las características generales base para iniciar estudios universitarios que trae el estudiante cuando ingresa a la UNJBG de Tacna está en un nivel adecuado. Las cualidades generales del perfil profesional que debe poseer el ingresante, expresados en actitudes para el estudio, aptitudes para la carrera y una firme práctica de valores, está en un nivel adecuado. Respecto a cualidades específicas del perfil profesional expresadas en poseer los conocimientos previos necesarios, tener las habilidades técnico-formativas y ser emprendedor se encuentra en un nivel adecuado.

SEGUNDA. Laaptitud vocacional de los estudiantes de primer año de las distintas carreras de la UNJBG, se caracteriza por la motivación que posee, las habilidades académicas de que dispone y los conocimientos previos con que cuenta al iniciar estudios, están en un nivel adecuado.

TERCERA. La correlación entre el perfil profesional que se exige para el postulante de las distintas carreras de la UNJBG, y la aptitud vocacional que tiene el ingresante, está alrededor de 0,80. Lo cual quiere decir que el $80 \%$ de la aptitud vocacional del estudiante universitario del primer año se explica linealmente por el perfil profesional que trae dicho estudiante a la universidad para iniciar estudios en alguna carrera profesional.

\section{BIBLIOGRAFÍA.}

- AUDAVE MUÑOZ, Daniel y otros (2010) Tesis: Dificultades que presentan los estudiantes universitarios en habilidades académicas básicas. México: XI Congreso de investigación educativa.Universidad autónoma de Aguascalientes. 
- PEÑAlOZA RAMELlA, Walter (2003): Los Propósitos de la Educación. Perú: Fondo Editorial del Pedagógico San Marcos.

- ROSSIQUIROZ, Elías (1993): El perfil profesional y la planificación curricular. Lima Perú.

- SERENO GARCÍA, Juvencio (2006): Valores y actitudes del estudiante técnico al ingreso y egreso de su formación universitaria. México. Revista regional de investigación educativa.

- UN/JBG. Planes Curriculares de las Escuelas Académico Profesionales.

\section{Correspondencia:}

Dionicio Milton Chávez Muñoz

Ciudad Universitaria Fundo "Los Granados"

Av. Miraflores s/n. Tacna. Perú.

miltondioni@hotmail.com 